\title{
I Sit but I Don't Know Why: Integrating Controlled and Automatic Motivational Precursors Within a Socioecological Approach to Predict Sedentary Behaviors
}

Silvio Maltagliati ( $\sim$ silvio.maltagliati@gmail.com )

Univ. Grenoble Alpes, SENS, F-38000 Grenoble, France 2 Department of Sport Sciences and Physical Education, Ecole Normale Superieure, Rennes, France https://orcid.org/0000-0001-7199-0599

Philippe Sarrazin

Universite Grenoble Alpes

Sandrine Isoard-Gautheur

Universite Grenoble Alpes

Ryan E. Rhodes

University of Victoria

Matthieu P. Boisgontier

University of Ottawa

\section{Boris Cheval}

Université de Genève: Universite de Geneve

\section{Research}

Keywords: sedentary behaviors, dual-process model, socioecological model, approach-avoidance, habits

Posted Date: September 4th, 2020

DOI: https://doi.org/10.21203/rs.3.rs-70750/v1

License: (c) (i) This work is licensed under a Creative Commons Attribution 4.0 International License. Read Full License 


\section{Abstract}

Background. Precursors driving leisure-time sedentary behaviors remain poorly investigated, despite their detrimental consequences. This study aimed to investigate the predictive validity of controlled and automatic motivational precursors toward reducing sedentary behaviors and being physically active on leisure-time sedentary behaviors. The influence of demographic, physical, socio-professional, interpersonal, and environmental variables on leisure-time sedentary behaviors was also examined and compared with the associations of motivational precursors.

Methods. 125 adults completed questionnaires measuring controlled motivational precursors (i.e., attitudes, intentions, perceived competence), demographical (i.e., sex and age), physical (i.e., body mass index), and interpersonal (i.e., number of children) variables. Regarding automatic motivational precursors, habit strength and approach-avoidance tendencies were captured using the Self-Report Behavioral Automaticity Index and a manikin task. Leisure time, time and physical activity at work were computed as socio-professional variables, days of the week and weather conditions were recorded as environmental precursors. Participants wore an accelerometer for seven days and leisure time was identified thanks to notebooks. Associations between the different precursors and the leisure-time sedentary behaviors were examined in linear mixed effect models.

Results. Intention to be physically active $(b=-1.089, p=.028)$ and habit strength toward physical activity $(b=-0.943, p=.019)$ were negatively associated with leisure-time sedentary behaviors. However, motivational precursors toward reducing sedentary behaviors were not associated with the dependent variable ( $p s$. > .098). Demographical $(b=5.043, p=.002$ for sex and $b=0.493, p=.011$ for body mass index), socio-professional ( $b=-1.318, p=.040$ for leisure time and $b=1.861, p=.005$ for time at work), interpersonal ( $b=-2.037, p=.002$ for the number of children), and environmental (i.e., $p=.028$ for the global effect of the day of the week and $p<.001$ for the global effect of the weather conditions) precursors were more strongly associated with leisure-time sedentary behaviors.

Conclusion. Our findings show that, in comparison with demographical, socio-professional, interpersonal and environmental variables, the influence of motivational precursors on leisure-time sedentary behaviors is limited. This study lends support for the adoption of a broad-spectrum of precursors when predicting sedentary behaviors.

\section{Introduction}

Sedentary behaviors, defined as any waking behavior in a reclining, sitting, or lying position that requires an energy expenditure lower than 1.5 Metabolic Equivalent Task (Sedentary Behavior Research Network, 2012), are associated with a wide range of detrimental health consequences, including adverse metabolic conditions (Hamilton et al., 2007), depression (Teychenne et al., 2010), and cognitive decline (Olanrewaju et al., 2020). Adults spend about $77 \%$ of their waking time being sedentary (Diaz et al., 2016) and workplace settings account for a large amount of this daily time (Saidj et al., 2015). To mitigate the 
detrimental consequences associated with such patterns of activity at work, reducing sedentary behaviors during leisure time seems particularly important (Patel et al., 2010). However, the main precursors underlying leisure-time sedentary behaviors remain poorly investigated.

\section{Explaining Sedentary Behaviors Through Sociocognitive Models}

In the past decade, a growing number of studies investigated the motivational precursors of sedentary behaviors (Biddle, 2011). Most of these studies were anchored within sociocognitive models, which are based on the premise that imagined end states (expectancies, goals) are proximal variables of behaviors (Brand \& Cheval, 2019). These models suggest that attitudes, intentions, and self-perceptions (e.g., perceived competence) orient individuals' actions toward or away from specific behaviors.

Previous work showed that positive affective attitudes (i.e., perceiving sedentary behaviors as something pleasant) (Busschaert et al., 2016) and positive instrumental attitudes (i.e., perceiving sedentary behaviors as something useful) (Prapavessis et al., 2015) toward sedentary behaviors were associated with greater time spent in sedentary behaviors. By contrast, higher intention to reduce sedentary behaviors was negatively associated with time spent in sedentary behaviors (Maher \& Conroy, 2015; Maher \& Dunton, 2020). Besides motivation toward sedentary behaviors, positive affective and instrumental attitudes toward physical activity (Ham et al., 2013), higher intention to be physically active (He et al., 2010; but see Maher \& Conroy, 2015 for null findings), and higher perceived competence to adopt a more active lifestyle (Bai et al., 2015; Quartiroli \& Maeda, 2014) were associated with lower time spent in sedentary behaviors. However, the associations between these motivational precursors and sedentary behaviors were only of small to medium magnitude, suggesting that others motivational variables may drive sedentary behaviors (Rollo et al., 2016). In this line, additional theoretical perspectives, such as the dual-process models (Rhodes et al., 2019), have been mobilized to explain sedentary behaviors.

\section{Explaining Sedentary Behaviors Through Dual-process Models}

Dual-process models contend that behaviors are governed by both controlled and automatic motivational processes (Strack \& Deutsch, 2004). Controlled processes are slow, initiated intentionally, require cognitive resources and effort, and operate within conscious awareness. The key aforementioned sociocognitive constructs are assumed to be "plugged" in this controlled dimension (Conroy \& Berry, 2017). Conversely, automatic processes are fast, initiated unintentionally, require relatively less cognitive resources and effort, occur outside conscious awareness (e.g., habits, automatic affective reactions, approach-avoidance tendencies). 
Despite the incidental enactment of sedentary behaviors (Spence et al., 2017), explained by the profusion of attention-grabbing cues in our modern environment (Levine, 2015), the influence of automatic motivational processes remains overlooked. Indeed, only a few studies have mobilized dual-process models to explain sedentary behaviors (Chevance et al., 2017; Conroy et al., 2013; Maher \& Conroy, 2015, 2016; Maher \& Dunton, 2019). Results showed that higher habit strength for sedentary behaviors (i.e., association between a contextual cue in the environment and a behavioral response, Gardner, 2015) was associated with higher time spent in sedentary behaviors (Conroy et al., 2013; Maher \& Conroy, 2015, 2016; Maher \& Dunton, 2019). Unlike results observed for the controlled motivational precursors, habit strength for physical activity was not associated with time spent in sedentary behaviors (Maher \& Conroy, 2015). One study assessed automatic affective attitudes toward sedentary behaviors (Chevance et al., 2017), using the Single Category Implicit Association Test, a reaction time-based task (Karpinski \& Steinman, 2006; Rebar et al., 2015), but did not observed association with time spent in sedentary behaviors.

Besides habits and automatic affective reactions, other automatic processes could be investigated, such as approach-avoidance tendencies (Cheval et al., 2014, 2015; Zenko \& Ekkekakis, 2019). Indeed, avoiding stimuli depicting sedentary behaviors triggered larger evoked-related potentials in the medial frontal cortex and frontocentral cortex, which are related to conflict monitoring and inhibition, respectively (Cheval et al., 2018). Consistent with the idea that sedentary behaviors are difficult to avoid (Cheval et al., 2020; Cheval et al., 2017), these results suggest that approach-avoidance tendencies could play an important role in the regulation of sedentary behaviors. However, no study has yet assessed the association between automatic approach-avoidance tendencies and sedentary behaviors.

Importantly, previous studies rarely distinguished between leisure-time and working-time sedentary behaviors (Conroy et al., 2013; Maher \& Conroy, 2015, 2016; Maher \& Dunton, 2019). This lack of distinction is understandable in older populations who are retired (Maher \& Conroy, 2016; Maher \& Dunton, 2019), but is questionable among active adults (Conroy et al., 2013; Maher \& Conroy, 2015).

Students and workers may hardly control the time spent in sedentary behaviors in the workplace or at the university because such contexts often constrain to engage in prolonged sitting activities (Saidj et al., 2015; Vandelanotte et al., 2013). In this line, while specific motivational precursors are expected to drive leisure-time sedentary behaviors (Owen et al., 2011), previous work may have blurred such associations by merging leisure time and working time. Moreover, as theorized by socioecological models (Owen et al., 2011), other variables, related to the individual and one's environment, could also contribute to better explain sedentary behaviors.

\section{Explaining Sedentary Behaviors Through Socioecological Models}

Socioecological models are based on the premise that behaviors are jointly driven by multiple determinants (Glass \& McAtee, 2006), which can be classified as intrapersonal, interpersonal, and 
environmental factors (O'Donoghue et al., 2016). Intrapersonal variables refer to demographic (e.g., gender, age) and physical factors (e.g., body mass index), as well as motivational and socio-professional factors (e.g., leisure time, working time, physical activity at work). Interpersonal variables include familial determinants, such as, the number of children. Alongside with built environmental determinants (e.g., accessibility to facilities), natural environmental factors can refer, to the days of the week or to weather conditions. Hence, far from competing with models focusing on motivational variables, the socioecological model integrates the aforementioned motivational precursors by considering individuals as actors amidst broader networks (Rhodes et al., 2019; Sniehotta et al., 2017).

To date, the application of the socioecological models to sedentary behaviors has mainly focused on demographic and physical precursors (see Chastin et al., 2015; O'Donoghue et al., 2016; Rhodes et al., 2012 for reviews). For example, being a male, older (e.g., Saidj et al., 2015), or having a greater BMI (e.g., Vandelanotte et al., 2009) were associated with higher time spent in sedentary behaviors. However, results were mixed regarding the influence of socio-professional variables on leisure-time sedentary behaviors. In line with the idea than an increase in physical activity may be subsequently compensated by an decrease in energy expenditure (Melanson, 2017), previous work revealed that greater level of physical activity at work was associated with higher sedentary behaviors during leisure time (e.g., Stamatakis et al., 2014). However, other studies did not reveal such relationship (Tigbe et al., 2011; Vandelanotte et al., 2013). Regarding interpersonal variables, having less children was associated with higher time spent in sedentary behaviors during leisure time (Van Uffelen et al., 2012). For environmental variables, higher time spent in leisure-time sedentary behaviors was observed on weekend days (Thorp et al., 2012), and on cloudy and rainy days (Chan \& Ryan, 2009).

While socioecological models emphasize the importance to map these different levels of influence on sedentary behaviors, previous work has mostly examined these variables in isolation (Buck et al., 2019; De Craemer et al., 2018). Although studies have jointly investigated the effects of motivational precursors with others variables (e.g., sex, body mass index, day of the week) (e.g., Conroy et al., 2013), no study has integrated socio-professional, interpersonal, and environmental factors alongside with controlled and automatic motivational variables to predict leisure-time sedentary behaviors. Importantly, recent findings suggested that demographic, physical, socio-professional, interpersonal, and environmental factors could exert a greater influence on sedentary behaviors than motivational variables (Buck et al., 2019). However, no study has directly compared the predictive validity of these variables within the same sample.

\section{The Current Study: An Integrative Approach}

The current study aimed to investigate the predictive validity of motivational (controlled and automatic), demographic, physical, socio-professional, interpersonal, and environmental precursors of leisure-time sedentary behaviors. Therefore, this study provides an integrative approach contributing to provide better understanding of the relative weight of motivational precursors in the regulation of sedentary behaviors 
(Fig. 1). To this end, 135 healthy workers' leisure-time sedentary behaviors were monitored for one week using an accelerometer and associations with aforementioned precursors were examined.

We hypothesized that both controlled and automatic motivational determinants predict leisure-time sedentary behaviors $(\mathrm{H} 1)$. Specifically, higher controlled $(\mathrm{H} 1$ a) (i.e., attitudes, intention, perceived competence) and automatic ( $\mathrm{H} 1$ b) (i.e., habit strength and approach-avoidance tendencies) motivation to reduce sedentary behaviors and to be physically active should negatively predict leisure-time sedentary behaviors. We also expected that demographic, physical, socio-professional, interpersonal, and environmental variables should predict leisure-time sedentary behaviors $(\mathrm{H} 2)$. Finally, we compared the strength of the associations between these variables and leisure-time sedentary behaviors. We did not formulate an priori hypothesis on the relative weight of these precursors, although recent work suggests that the association between motivational precursors and leisure-time sedentary behaviors may be weaker than associations with the other variables (Buck et al., 2019).

\section{Methods}

\section{Participants And Procedure}

This manuscript contains data from two published studies (Cheval et al., 2015, 2016). A detailed description of the recruitment and experimental procedure is provided in supplementary material. First, 135 working adults completed a computerized reaction-time task and questionnaires assessing the different motivational precursors. Then, each participant received an accelerometer and received a notebook. They were invited to indicate on the notebook the time at which they woke up, put the accelerometer on their hip, arrived at their workplace, quit their workplace, removed the accelerometer, and went to bed. Participants were also asked to indicate whether they felt ill or injured during the monitoring period. Daily weather conditions, day of the week, and day in the monitoring sequence were collected over the course of the week by a research assistant. Eight days later, participants gave back their accelerometer and their notebook, and were debriefed.

\section{Measures}

Device-based measure of sedentary behaviors during leisure time

A three-axis accelerometer (Actigraph GT3X+; Pensacola, USA) was used to quantify sedentary behaviors for seven days in free-living conditions. When data met the inclusion, criteria listed below, the eighth day of wear (i.e., when participants came back to the laboratory), was included in the analyses. One-minute epochs were used for data analyses and non-wear time was defined as $\geq 59$ consecutive minutes of zero counts. Daily data were included if they met two conditions: a wear time $\geq$ ten waking hours per day (Evenson \& Terry, 2009) and a wear time during leisure time $\geq$ four hours or $\geq 75 \%$ of the average reported leisure-time (Gupta et al., 2016; Rasmussen et al., 2019). Working and leisure time were identified based on notebook reports. Data were included if $\geq$ four days met the aforementioned conditions and 
included one weekend day (Matthews et al., 2012). Of 1080 possible days, 786 were included in the study (Fig. 2). Time spent in sedentary behaviors was determined through previously validated cut-points (i.e., 0 to 100 counts/min) (Freedson et al., 1998). To standardize for differences in leisure time between and within participants, the dependent variable was the daily percentage of leisure time spent in sedentary behaviors (Healy et al., 2011).

Controlled and automatic motivational precursors

Affective and instrumental attitudes toward sedentary behaviors and physical activity, intention to reduce sedentary behaviors and to be physically active, perceived competence to adopt an active lifestyle, habit strength toward sedentary behaviors and physical activity were measured using questionnaires. A detailed description of the scales is provided in supplementary material.

The automatic approach-avoidance tendencies toward sedentary behaviors and toward physical activity were assessed using a manikin task (Krieglmeyer \& Deutsch, 2010) (see Cheval et al., 2015 for a detailled description). The automatic tendency to approach sedentary behaviors was calculated by subtracting the median reaction time when approaching sedentary stimuli from the median reaction time when avoiding sedentary stimuli - a higher score indicating a higher tendency to approach (vs. avoid) sedentary stimuli. The same logic was applied to calculate the automatic approach tendency toward physical activity. Two participants were excluded from the study because they demonstrated extreme scores (i.e., more than four standard deviations away from the sample mean, which consists into a commonly used threshold to detect outliers, Cousineau \& Chartier, 2010).

Demographic, physical, socio-professional, interpersonal and environmental precursors

Sex and age were included as demographic variables, body mass index as a physical variable, and the number of children as an interpersonal precursor.

\section{Leisure time}

Daily leisure time, expressed in minutes, was computed on the basis of notebook reports. This variable had two levels: an average between-person level, centered on the average value of the sample, and a daily within-person level, centered on the average value of each participant. This bidimensional approach accounted for both inter-individual differences in leisure-time and intra-individual changes across monitoring days for a given participant.

\section{Time spent at work and time spent in physical activity at work}

These two variables were computed by matching notebook reports with accelerometer measures. Time spent in moderate-to-vigorous physical activity was identified by using previously validated cut-points (i.e., > 1952 counts/min) (Freedson et al., 1998). As mentioned for leisure time, these variables were separated into two dimensions: an average between-person level and a daily within-person level (Table S1). 
Day of the week

Days of the week were dummy coded. Saturdays served as the reference category as the lowest levels of leisure time sedentary were observed on this day (Table S2).

\section{Daily weather conditions}

Daily weather conditions were obtained over the study period from the website MeteoFrance.com and coded by a research assistant. Three levels were created: sunny, cloudy, or rainy. Sunny days served as the reference category because the lowest levels of leisure-time sedentary behaviors were observed on these days (Table S2).

Confounding variables

IIIness or injury were added as a confounding variable because they were a potential source of higher time spent in sedentary behaviors (Maher \& Conroy, 2016). Based upon participants' notebook, a dichotomous variable was coded ( 1 for people who reported an illness or an injury; 2 for people who did not report any illness or injury). Finally, day in the monitoring sequence was included as a confounding variable as self-monitoring procedures have been shown to influence sedentary behaviors across days of wear (Motl et al., 2012).

\section{Statistical Analyses}

Associations of predictors with the percentage of leisure-time spent in sedentary behaviors were analyzed using mixed effects models. This approach allows to account for the nested structure of the data (here, multiple observations within a single participant). Moreover, mixed effects models do not require an equal number of observations from all participants and increases power compared with traditional approaches, such as linear regressions (Boisgontier \& Cheval, 2016; Judd et al., 2017). All models had random intercepts for participants and random slopes were added for all the time-varying variables (Frossard \& Renaud, 2019).

First, we estimated a base model (M0), which tested the associations between the confounding variables (i.e., day in the monitoring sequence, and illness or injury) and leisure-time sedentary behaviors. All the subsequent models were adjusted for these confounders. In a first set of models (Ms1), we separately added each controlled and automatic motivational variables to M0. This "one-by-one" strategy was used to account for the substantial shared variance between some of these constructs (Table S3). In a second set of models (Ms2), we separately added each demographic and physical variable to M0. In a third set of models (Ms3), we separately added each socio-professional variable to M0. This set of models Ms3 was adjusted for the day of the week as socio-professional variables and days of the week were closely related (Table S2). In a fourth model (M4), we added interpersonal variables (i.e., number of children). In a fifth set of models (Ms5), we separately added environmental variables. Variables which were significantly associated with leisure-time sedentary behaviors in Ms1, Ms2, Ms3, M4 and Ms5 were 
identified on the basis of the $p$-value $(p<.05)$ and were gathered in a last parsimonious final model (M6) ${ }^{1}$. To examine whether the different variables included contributed to improve the fit of the final model M6, this final model was tested against models in which the variables of interest were removed. Variables which increased the fit of the models were identified on the basis of the Bayesian Information Criterion (BIC), -2-log-likehood (-2LL) and p-values (Bollen et al., 2014). All models were estimated using the Ime4 and ImerTest packages in the R software (Bates et al., 2014; Kuznetsova et al., 2015). An estimate of the effect size for fixed effects was reported using the marginal pseudo- $R^{2}$, computed using the MuMin package (Barton, 2009). Statistical assumptions associated with mixed models were checked (including normality of the residuals, homogeneity of variance, linearity, multicollinearity, and undue influence) and met for all the models.

\section{Results}

Descriptive results are presented in Table 1. The final sample included 125 adults (age $=40 \pm 9$ years; body mass index $=24 \pm 4 ; 75$ women; $74 \%$ with at least one child). The average percentage of sedentary behaviors during leisure time was $58 \pm 12 \%$, corresponding to $5 \mathrm{~h} 38 \mathrm{~min} \pm 2 \mathrm{~h} 21 \mathrm{~min}$ per day. 
Table 1

Descriptive statistics and results of the mixed models testing the association between each variable and leisure-time sedentary behaviors

\section{Descriptive statistics Mixed models}

$\begin{array}{lllllll}\text { Variables } & \substack{\text { Mean } \pm \\ \text { SD }} & \text { Range } & b[95 \% \mathrm{Cl}] & \mathrm{SE} & \mathrm{p} & \mathbf{R}^{2}\end{array}$

Model 0: Confounding variables

$\begin{array}{lllllll}\text { Day in the monitoring } & - & - & \begin{array}{l}0.127[-0.220 ; \\ 0.476]\end{array} & 0.177 & .474 & .030 \\ \text { sequence } & & & \begin{array}{l}0.152[2.457 ; \\ 13.856]\end{array} & 2.909 & .006^{\star *} \\ \text { IIIness and injury (\%) } & 8 & - & & \end{array}$

Models 1: Controlled motivational variables

\begin{tabular}{|c|c|c|c|c|c|c|}
\hline $\begin{array}{l}\text { Affective attitudes toward } \\
\text { SB }\end{array}$ & $\begin{array}{l}6.52 \pm \\
1.14\end{array}$ & $3.38-9.00$ & $\begin{array}{l}0.922[0.663 \\
2.503]\end{array}$ & 0.809 & .276 & .034 \\
\hline $\begin{array}{l}\text { Affective attitudes toward } \\
\text { PA }\end{array}$ & $\begin{array}{l}6.33 \pm \\
0.99\end{array}$ & $4.00-8.50$ & $\begin{array}{l}-1.268[-2.609 \\
0.069]\end{array}$ & 0.684 & $.066^{\wedge}$ & .046 \\
\hline $\begin{array}{l}\text { Instrumental attitudes } \\
\text { toward SB }\end{array}$ & $\begin{array}{l}5.53 \pm \\
1.11\end{array}$ & $2.62-8.5$ & $\begin{array}{l}-0.152[-1.567 ; \\
1.256]\end{array}$ & 0.715 & .779 & .030 \\
\hline $\begin{array}{l}\text { Instrumental attitudes } \\
\text { toward PA }\end{array}$ & $\begin{array}{l}7.49 \pm \\
1.00\end{array}$ & $4.5-9.0$ & $\begin{array}{l}-0.628[-2.178 \\
0.923]\end{array}$ & 0.795 & .431 & .032 \\
\hline Intention toward SB & $\begin{array}{l}4.32 \pm \\
1.57\end{array}$ & $1.00-6.00$ & $\begin{array}{l}-0.617[-1.621 \\
0.390]\end{array}$ & 0.513 & .231 & .035 \\
\hline Intention toward PA & $\begin{array}{l}4.09 \pm \\
1.62\end{array}$ & $1.00-6.00$ & $\begin{array}{l}-1.089[-2.048 \\
-0.127]\end{array}$ & 0.489 & $.028^{*}$ & .047 \\
\hline Perceived competence & $\begin{array}{l}5.06 \pm \\
1.18\end{array}$ & $1.4-7.00$ & $\begin{array}{l}-1.251[-2.543 \\
0.0413]\end{array}$ & 0.662 & .061 & .042 \\
\hline
\end{tabular}

Models 1: Automatic motivational variables

\begin{tabular}{|c|c|c|c|c|c|c|}
\hline Habit strength toward SB & $\begin{array}{l}4.18 \pm \\
1.64\end{array}$ & $1.00-7.00$ & $\begin{array}{l}0.793[-0.135 ; \\
1.720]\end{array}$ & 0.475 & $.098^{\wedge}$ & .041 \\
\hline Habit strength toward PA & $\begin{array}{l}3.97 \pm \\
1.96\end{array}$ & $1.00-7.00$ & $\begin{array}{l}-0.940[-1.712 \\
-0.168]\end{array}$ & 0.476 & $.019 *$ & .051 \\
\hline $\begin{array}{l}\text { Approach-avoidance } \\
\text { tendencies toward SB }\end{array}$ & $\begin{array}{l}-109.61 \pm \\
227.78\end{array}$ & $\begin{array}{l}-964.5- \\
335.5\end{array}$ & $\begin{array}{l}0.003[-0.003 \\
0.010]\end{array}$ & 0.003 & .345 & .033 \\
\hline $\begin{array}{l}\text { Approach-avoidance } \\
\text { tendencies toward PA }\end{array}$ & $\begin{array}{l}28.72 \pm \\
216.41\end{array}$ & $\begin{array}{l}-961.5- \\
469.0\end{array}$ & $\begin{array}{l}0.003[-0.004 \\
0.010]\end{array}$ & 0.004 & .471 & .031 \\
\hline
\end{tabular}

Models 2: Demographic and physical variables

$\begin{array}{lllllll}\text { Sex }(\% \text { of men }) & 40 & - & 5.043[1.935 ; & 1.591 & .002^{\star \star} & .066 \\ & & 8.147] & & & \end{array}$




\begin{tabular}{|c|c|c|c|c|c|c|}
\hline \multirow[b]{2}{*}{ Age } & \multicolumn{2}{|c|}{ Descriptive statistics } & \multicolumn{4}{|l|}{ Mixed models } \\
\hline & $\begin{array}{l}39.74 \pm \\
8.78\end{array}$ & $22-57$ & $\begin{array}{l}-0.128[-0.301 ; \\
0.050]\end{array}$ & 0.090 & .159 & .037 \\
\hline Body mass index & $\begin{array}{l}24.00 \pm \\
4.05\end{array}$ & $\begin{array}{l}17.22- \\
41.14\end{array}$ & $\begin{array}{l}0.493[0.117 \\
0.866]\end{array}$ & 0.191 & $.011^{\star}$ & .054 \\
\hline \multicolumn{7}{|c|}{ Models 3: Socio-professional variables } \\
\hline \multicolumn{7}{|l|}{ Leisure time (in min) } \\
\hline Between-person level & $\begin{array}{l}595.08 \pm \\
77.91\end{array}$ & $401-817$ & $\begin{array}{l}-0.026[-1.046 \\
0.996]\end{array}$ & 0.521 & .961 & \multirow[t]{2}{*}{.032} \\
\hline Within-person level & $\begin{array}{l}0.00 \pm \\
221.54\end{array}$ & $\begin{array}{l}-499.4- \\
578\end{array}$ & $\begin{array}{l}-1.331[-2.591 \\
-0.074]\end{array}$ & 0.644 & $.040 *$ & \\
\hline \multicolumn{7}{|l|}{ Time at work (in min) } \\
\hline Between-person level & $\begin{array}{l}228.80 \pm \\
76.91\end{array}$ & $\begin{array}{l}32.67- \\
469.62\end{array}$ & $\begin{array}{l}0.164[-0.852 ; \\
1.179]\end{array}$ & 0.656 & .752 & \multirow[t]{2}{*}{.049} \\
\hline Within-person level & $\begin{array}{l}0.00 \pm \\
248.61\end{array}$ & $\begin{array}{l}-469.62- \\
529.83\end{array}$ & $\begin{array}{l}1.861[0.578 \\
3.141]\end{array}$ & 0.519 & $.005^{\star \star}$ & \\
\hline $\begin{array}{l}\text { Percentage of MVPA at } \\
\text { work (in \%) }\end{array}$ & & & - & - & - & - \\
\hline Between-person level & $\begin{array}{l}0.00 \pm \\
2.04\end{array}$ & $\begin{array}{l}-1.52- \\
13.09\end{array}$ & $\begin{array}{l}0.180[-0.181 \\
0.541]\end{array}$ & 0.184 & .327 & .042 \\
\hline Within-person level & $\begin{array}{l}0.00 \pm \\
3.76\end{array}$ & $\begin{array}{l}-14.65- \\
31.6\end{array}$ & $\begin{array}{l}0.153[-0.096 \\
0.402]\end{array}$ & 0.127 & .230 & \\
\hline \multicolumn{7}{|c|}{ Model 4: Interpersonal variables } \\
\hline Number of children & $\begin{array}{l}1.540 \pm \\
1.230\end{array}$ & $0-6$ & $\begin{array}{l}-2.0371 \\
{[-3.264} \\
-0.811]\end{array}$ & 0.625 & $.002^{\star \star}$ & .068 \\
\hline \multicolumn{7}{|c|}{ Models 5: Environmental variables } \\
\hline Day of the week & - & - & 14.146 & & .028 & \multirow[t]{5}{*}{.040} \\
\hline Monday (\% of all days) & 15.013 & - & $\begin{array}{l}2.937[0.466 \\
5.405]\end{array}$ & 1.263 & $.020 *$ & \\
\hline Tuesday (\% of all days) & 12.214 & - & $\begin{array}{l}1.980[-0.593 \\
4.570]\end{array}$ & 1.321 & .133 & \\
\hline Wednesday (\% of all days) & 14.885 & - & $\begin{array}{l}0.934[-1.513 \\
3.375]\end{array}$ & 1.249 & .455 & \\
\hline Thursday (\% of all days) & 13.359 & - & $\begin{array}{l}1.401[-1.119 \\
3.922]\end{array}$ & 1.291 & .278 & \\
\hline
\end{tabular}




\begin{tabular}{|llllll|}
\hline & \multicolumn{3}{l}{ Descriptive statistics } & \multicolumn{2}{l|}{ Mixed models } \\
\hline
\end{tabular}

\section{Confounding Variables And Sedentary Behaviors (m0)}

Absence of injury/illness during the monitoring sequence was associated with lower leisure-time sedentary behaviors $(b=8.152,95 \%$ confidence interval $(95 \mathrm{Cl})=[2.457 ; 13.856], p=.006)$. However, position of the day in the monitoring period was not related with sedentary behaviors during leisure time $(p=.474)$. This model explained $3.0 \%$ of the variance in leisure-time sedentary behaviors.

\section{Motivational Precursors And Sedentary Behaviors (ms1)}

For controlled motivational variables, intention to be physically active was negatively associated with leisure-time spent sedentary behaviors $(b=-1.089,95 \mathrm{Cl}=[-2.048 ; 0.127], p=.028)$. Moreover, marginal negative associations of affective attitudes toward physical activity $(b=-1.268,95 \mathrm{Cl}=[-2.609 ; 0.069], p$ $=.066)$ and perceived competence $(b=-1.251,95 \mathrm{Cl}=[-2.543 ; 0.041], p=.061)$ with leisure-time spent sedentary behaviors were observed.

For automatic motivational variables, habit strength toward physical activity was negatively associated with leisure-time sedentary behaviors $(b=-0.943,95 \mathrm{Cl}=[-1.712 ;-0.168], p=.019)$. In addition, a marginal association between habit strength toward sedentary behaviors and leisure-time sedentary behaviors $(\mathrm{b}=$ $0.793,95 \mathrm{Cl}=[-0.134 ; 1.720], p=.098)$ was observed. In contrast, automatic approach-avoidance tendencies toward sedentary behaviors or physical were not associated with leisure-time sedentary behaviors ( $p s>$.345).

Demographic, Physical, Socio-Professional, Interpersonal And Environmental Precursors And Sedentary Behaviors (Ms2, Ms3, M4, Ms5) 
For demographic and physical variables (Ms2), men (vs. women) $(b=5.043,95 \mathrm{Cl}=[1.935 ; 8.147], p$ $=.002)$ and higher body mass index $(b=0.493,95 \mathrm{Cl}=[0.117 ; 0.866], p=.011)$ were associated with higher time spent in sedentary behaviors during leisure time (Table 1). Age was not associated with the dependent variable $(p=.159)$.

- Regarding socio-professional variables (Ms3), leisure time at the within-person level $(b=-1.318,95 \%$ $\mathrm{Cl}[-2.591 ;-0.074], p=.040)$, time at work at the within-person level $(b=1.861,95 \mathrm{Cl}[0.578 ; 3.141], p$ $=.005)$ were associated with leisure-time sedentary behaviors. However, time spent in moderate-tovigorous physical activity at work was not associated with leisure-time sedentary behaviors, neither at the between-person level, nor at the within-person level ( $p s .>.230)$.

For interpersonal variables (M4), number of children $(b=-2.037,95 \mathrm{Cl}=[-3.264 ;-0.811], p=.002)$ was negatively associated with leisure-time sedentary behaviors.

Regarding environmental variables (Ms5), the day of the week was associated with leisure-time sedentary behaviors ( $p$ for global effect $=.028$ ). Compared to Saturdays, leisure-time sedentary behaviors was higher on Mondays $(b=2.937,95 \mathrm{Cl}=[0.466 ; 5.405], p=.020)$, Fridays $(b=2.719,95 \mathrm{Cl}=[0.291 ; 5.152], p$ $=.029)$ and Sundays $(b=4.087,95 \mathrm{Cl}=[1.658 ; 6.514], p=.001)$. Daily weather conditions were also associated with leisure-time sedentary behaviors ( $p$ for global effect $<.001$ ). Compared to sunny days, leisure-time sedentary behaviors was higher on cloudy days $(b=2.586,95 \mathrm{Cl}=[0.612 ; 4.560], p=.012)$ and rainy days $(b=4.949,95 \mathrm{Cl}=[2.613 ; 7.285], p<.001)$.

\section{Motivational, Demographic, Physical, Socio-Professional, Interpersonal and Environmental Precursors and Sedentary Behaviors}

The full final model (M6) included the following variables: injury/illness, day in the monitoring sequence, intention to be physically active, habit strength toward physical activity, sex, body mass index, leisure time, time at work, number of children, day of the week, and daily weather conditions (Table 2) (Fig. 3). $\operatorname{Sex}(b=3.754,95 \mathrm{Cl}=[0.812 ; 6.685], p=.016)$, time spent at work $(b=2.053,95 \mathrm{Cl}=[0.327 ; 3.791), \mathrm{p}$ $=.021)$, number of children $(b=-1.917,95 \mathrm{Cl}=[-3.033 ;-0.808], p s<.001)$, daily weather conditions $(b=$ $3.283,95 \mathrm{Cl}=[1.103 ; 5.498], p=.009$ for cloudy days, $\mathrm{b}=3.710,95 \mathrm{Cl}=[1.102 ; 6.290], p=.018$ for rainy days), and days of the week ( $p=.027$ for global effect, $\mathrm{b}=-3.747,95 \mathrm{Cl}=[-7.040 ;-0.485], p=.026$ for Thursdays, $\mathrm{b}=2.841,95 \mathrm{Cl}=[0.346 ; 5.333] p=.027$ for Sundays) remained associated with leisure-time sedentary behaviors. Injury or illness was marginally associated with leisure-time sedentary behaviors (b $=4.896,95 \mathrm{Cl}[-0.407 ; 10.164], p=.080)$. Finally, intention to be physically active, habit strength toward physical activity, body mass index, and leisure time were no longer associated with leisure-time sedentary behaviors $(p s>.119)^{2}$. 
Table 2

Final model M6 gathering significant predictive variables of leisure-time sedentary behaviors during leisure time

\begin{tabular}{|c|c|c|c|}
\hline Fixed effects & $\mathrm{b}[95 \mathrm{Cl}]$ & SE & $p$ \\
\hline \multicolumn{4}{|l|}{ Motivational variables } \\
\hline Intention toward PA & $-0.403[-1.588 ; 0.787]$ & 0.629 & .518 \\
\hline Habit strength toward PA & $-0.584[-1.545 ; 0.367]$ & 0.502 & .245 \\
\hline \multicolumn{4}{|l|}{ Demographic and physical variables } \\
\hline $\operatorname{Sex}^{\mathrm{a}}$ & $3.754[0.812 ; 6.685]$ & 1.543 & $.016^{\star}$ \\
\hline Body mass index & $0.301[-0.065 ; 0.665]$ & 0.192 & .119 \\
\hline \multicolumn{4}{|l|}{ Socio-professional variables } \\
\hline Leisure time (within-person level) & $0.353[-1.382 ; 2.097]$ & 0.895 & .693 \\
\hline Time at work (within-person level) & $2.053[0.327 ; 3.791]$ & 0.891 & $.021^{\star}$ \\
\hline \multicolumn{4}{|l|}{ Interpersonal variables } \\
\hline Number of children & $-1.917[-3.033 ;-0.808]$ & 0.596 & $.001^{* *}$ \\
\hline \multicolumn{4}{|l|}{ Environmental variables } \\
\hline \multicolumn{4}{|l|}{ Day of the week } \\
\hline Saturday & ref & ref & ref \\
\hline Monday & $-0.527[-3.573 ; 2.512]$ & 1.564 & .736 \\
\hline Tuesday & $-1.343[-4.430 ; 1.719]$ & 1.580 & .396 \\
\hline Wednesday & $-1.678[-4.46 ; 1.078]$ & 1.424 & .239 \\
\hline Thursday & $-3.747[-7.040 ;-0.485]$ & 1.680 & $.026^{\star}$ \\
\hline Friday & $-0.189[-2.914 ; 2.527]$ & 1.398 & .893 \\
\hline Sunday & $2.841[0.346 ; 5.333]$ & 1.281 & $.027 *$ \\
\hline \multicolumn{4}{|l|}{ Daily weather conditions } \\
\hline Sunny days & ref & ref & ref \\
\hline Cloudy days & $3.283[1.103 ; 5.498]$ & 1.220 & $.009 * \star$ \\
\hline Rainy days & $3.710[1.102 ; 6.290]$ & 1.761 & $.018^{\star \star}$ \\
\hline \multicolumn{4}{|l|}{ Confounding variables } \\
\hline Day in the monitoring sequence & $-0.082[-0.440 ; 0.276]$ & 0.187 & .656 \\
\hline
\end{tabular}




\begin{tabular}{|llll|}
\hline Fixed effects & $\mathbf{b}[95 \mathrm{Cl}]$ & SE & $\boldsymbol{p}$ \\
\hline Illness or injury $\mathrm{b}$ & $4.896[-0.407 ; 10.164]$ & 2.819 & $.080^{\wedge}$ \\
\hline Random Effects & & & \\
\hline Subjects & & & \\
\hline Sunny days & 45.996 & & \\
\hline Rainy days & 67.449 & \\
\hline Cloudy days & 32.143 & \\
\hline Leisure time & 10.394 & \\
\hline Time at work & 0.004 & \\
\hline Day in the monitoring sequence & 0.099 & \\
\hline Residuals & 73.273 & \\
\hline Pseusdo-R & 0.162 & \\
\hline
\end{tabular}

Comparisons of models showed that motivational variables entered in the final model $(B I C=6033.6,-2 \mathrm{LL}$ $\left.=-2956.8, \chi^{2}=534.230, p<.001\right)$ marginally contributed to improve the fit of the final model $(\triangle \mathrm{BIC}=$ $\left.-8.100, \Delta-2 \mathrm{LL}=2.600, \chi^{2}=5.207, p=.074\right)$. By contrast, demographic and physical variables $(\triangle \mathrm{BIC}=$ $\left.1.800, \Delta-2 \mathrm{LL}=-5.700, \chi^{2}=11.528, p=.003\right)$, socio-professional $\left(\Delta \mathrm{BIC}=4.400, \Delta-2 \mathrm{LL}=4.500, \chi^{2}=9.987, p\right.$ $=.011$, interpersonal variables $\left(\Delta \mathrm{BIC}=-4.100, \Delta-2 \mathrm{LL}=5.400, \chi^{2}=10.811, p=.001\right)$, and environmental variables $\left(\triangle \mathrm{BIC}=-17.500, \Delta-2 \mathrm{LL}=17.900, \chi^{2}=35.848, p<.001\right)$ contributed to improve the fit of the final model.

Fixed effects entered in the full final model M5 explained $16.1 \%$ of the variance in leisure-time sedentary behaviors. Demographic and physical, interpersonal and environmental variables explained the higher part of variance with, $3.4 \%, 3.5 \%$ and $3.1 \%$, respectively. Motivational and socio-professional precursors accounted only for $1.4 \%$ and $0.9 \%$ of explained variance.

\section{Discussion}

This study investigated the predictive validity of motivational (controlled and automatic), demographic, physical, socio-professional, interpersonal, and environmental precursors of daily leisure time spent in sedentary behaviors. Findings suggested weak predictive validity of motivational variables relative to demographic, physical, interpersonal, and environmental determinants. Hence, our study supports previous work suggesting a limited influence of motivational variables on sedentary behaviors (Buck et al., 2019). 


\section{Comparison With Previous Studies}

Contrary to hypothesis $\mathrm{H} 1 \mathrm{a}$, controlled motivational variables toward sedentary behaviors were not related to leisure-time sedentary behaviors. This result contrasts with previous literature showing an association of affective and instrumental attitudes toward sedentary behaviors and intentions to reduce sedentary behaviors with leisure-time sedentary behaviors (Rollo et al., 2016). This discrepancy could be explained by differences in the measurement method. While previous work focused on a specific sedentary behavior (e.g., daily time spent watching TV) and assessed the respective specific affective and instrumental attitudes (e.g., attitudes toward watching TV) (e.g., Rhodes \& Dean, 2009), our study examined the influence of attitudes toward a large range of sedentary behaviors on global leisure-time sedentary behaviors. Likewise, our measure of the intention to reduce sedentary behaviors was derived from a time threshold (i.e., spending no more than four sedentary behaviors a day during leisure time). Yet, such global estimation may not represent an organizing target for the regulation of individuals' behaviors because sitting activities are hardly mentally represented (Gardner et al., 2019). Nonetheless, this non-significant association between the overall intention to reduce sedentary behaviors and leisuretime sedentary behaviors was already observed in previous work (Maher \& Conroy, 2016; Maher \& Dunton, 2019), thereby pointing out that intention may not be sufficient to reduce sedentary behaviors. In this line, volitional strategies, such as action planning and coping planning (Gollwitzer \& Sheeran, 2006;

Schwarzer, 2008) could play an important role in bridging the gap between intention and behaviors (Rollo \& Prapavessis, 2020; Sui \& Prapavessis, 2018).

Consistent with hypothesis $\mathrm{H} 1 \mathrm{a}$ and previous research (Rollo et al., 2016), controlled motivational variables toward physical activity were negatively associated with leisure-time sedentary behaviors ${ }^{2}$. Although only the association with intention was significant, these findings emphasize that controlled motivational precursors toward physical activity exert a protective, though limited, effect against the accumulation of leisure-time sedentary behaviors. This result can be accounted by a displacement effect (Rhodes \& Blanchard, 2011), suggesting that a desire for one activity, such as physical activity, will take away time spent in a competing activity, such as sedentary behaviors. Indeed, previous work evidenced a weak-to-moderate inverse association between time spent physical activity and in sedentary behaviors (Mansoubi et al., 2014). This rational is in accordance with the dual-hinge approach (Spence et al., 2017), explaining that the reduction in leisure-time sedentary behaviors implies their substitution by more physically active behaviors, even the lightest ones, such as standing or walking slowly (Prince et al., 2014). Therefore, motivation toward more physically active behaviors can be conceived as important adjuvants in the reduction of sedentary behaviors.

In line with hypothesis H1b and previous literature (Conroy et al., 2013; Maher \& Conroy, 2015, 2016; Maher \& Dunton, 2019), higher habit strength toward sedentary behaviors was marginally associated with higher leisure-time sedentary behaviors. Moreover, consistent with the displacement effect (Rhodes \& Blanchard, 2011), higher habit strength toward physical activity was associated with lower leisure-time sedentary behaviors. Finally, associations between automatic approach-avoidance tendencies and leisure-time sedentary behaviors were not evidenced. This finding may suggest that, when assessed 
using reaction-time tasks specifically designed to capture automatic reactions (Hagger, 2020; Rebar et al., 2018), automatic motivational variables can harldy explain sedentary behaviors.

Anchored within the socioecological framework (Owen et al., 2011), the present work revealed that demographic, physical, socio-professional, interpersonal and environmental variables were associated with leisure time spent in sedentary behaviors (H2). As found in previous studies (O'Donoghue et al., 2016), men and individuals with higher body mass index exhibited higher leisure-time sedentary behaviors. Regarding socio-professional variables, the results showing that sedentary behaviors during leisure time were higher on days in which individuals had less leisure time than usual and spent more time at work than usual is in line with previous work (Stamatakis et al., 2014). These results suggest that engaging in sedentary behaviors can serve as a way to rest after a demanding working day (Rawlings et al., 2019). The observation that leisure-time sedentary behaviors was higher on Sundays, a day usually devoted to the recovering of energy (Thorp et al., 2012), provide additional support for this idea.

Regarding interpersonal precursors, as already evidenced (see O'Donoghue et al., 2016 for a review), individuals with a higher number of children engaged in less leisure-time sedentary behaviors, suggesting that family commitment could protect from engaging in excessive sedentary behaviors. Moreover, for environmental factors, in comparison with sunny days, leisure-time sedentary behaviors were higher on cloudy and rainy days, underlining that natural environmental settings can represent an important barrier in reducing sedentary behaviors (Chan \& Ryan, 2009).

This study revealed that, in comparison with demographic and physical, socio-professional, interpersonal and environmental factors, motivational precursors explained only a weak proportion of leisure-time sedentary behaviors. Importantly, motivational precursors were no longer associated with sedentary behaviors once the other variables were included in the models. These results suggest a weak, marginal, effect of motivational precursors on sedentary behaviors. At the theoretical level, these findings echo a recent theory contending that humans are automatically attracted to effort minimization (Cheval et al., 2018; Cheval, et al., 2017). This attraction may explain why sedentary behaviors are difficult to avoid (Cheval et al., 2020; Cheval et al., 2018) and why motivational precursors alone can hardly prevent engagement in sedentary behaviors. In this view, environmental interventions (e.g., nudges) have proven

to be more effective in reducing sedentary behaviors than interventions targeting motivational variables (Blackburn et al., 2020; Gardner et al., 2016).

\section{Strengths And Limitations}

The present study includes the following strengths. First, we assessed and compared a broad range of potential precursors of leisure-time sedentary behaviors. In this perspective, the present work paves the way to future work interested in mapping potential interactions between these levels of influence, as showed in the physical activity domain (Rhodes et al., 2006). Second, although Actigraph GT3-X + tends to overestimate sedentary behaviors, in comparison with the ActivPal (Migueles et al., 2017), it provides 
an acceptable evaluation of sedentary behaviors in comparison with self-reported measurement (Gardner et al., 2019). Finally, we used a refined statistical analysis suited to examine daily-basis associations.

Several limitations should be considered. First, our findings should be interpreted with caution as, unlike previous studies (e.g., Maher \& Dunton, 2019), our study did not assess the daily (or hourly) fluctuations in motivational variables. This feature may explain the weak associations observed in the current study (Rebar et al., 2020). Second, leisure time and working time were identified thanks to notebooks reports, which may have led to approximative segmentation of these periods. Combining accelerometric measurement with global-positioning systems (GPS) could enable future research to refine the identification of the context in which sedentary behaviors occur (Jankowska et al., 2015).

\section{Conclusion}

This study shows that demographic, physical, interpersonal and environmental variables are associated with leisure-time sedentary behaviors, while the associations with controlled and automatic motivational precursors are weaker. As suggested by the socioecological framework, adopting a theoretical integrative perspective encompassing a large range of precursors can help to better characterizing the key variables involved in sedentary behaviors. These findings also suggest that interventions aiming to reduce leisuretime sedentary behaviors should pay attention to the specificities of the targeted people (i.e., men, individuals with higher body mass index, childless). Interventions could also benefit from strategies enabling individuals to cope with environmental conditions to reduce sedentary behaviors over the course of the week and on days with adverse weather conditions. By contrast, focusing on motivational variables could be rather ineffective.

\section{Declarations}

Ethics approval and consent to participate: Ethical approval for the study was granted by the University of Grenoble Research Ethics Committee.

Consent for publication: Not applicable.

Availability of data and materials: The datasets generated and/or analysed during the current study are available in the Zenodo repository, [doi: 10.5281/zenodo.4010153]

Competing interests: The authors declare that they have no competing interests.

Funding: B.C. is supported by an Ambizione grant (PZ00P1_180040) from the Swiss National Science Foundation (SNSF).

\section{Authors' contributions}

SM, PS, BC conceived the study. BC and SIG collected the data. SM, BC analyzed the data. SM, MPB, PS, $\mathrm{BC}$ drafted the manuscript. All authors contributed to the improvement of the manuscript and approved 
its final version.

Footnotes

${ }^{1}$ Influence of precursors which were marginally associated $(p<.10)$ with leisure-time

sedentary behaviors was also tested in a parsimonious model. This model M7 is presented in supplemental material (Table S4).

${ }^{2}$ When controlling for demographic, physical, socio-professional, interpersonal, and environmental variables, motivational precursors which were marginally associated with the leisure-time sedentary behaviors (i.e., affective attitudes toward physical activity, competence and habit strength toward sedentary behaviors) were no longer associated with leisure-time sedentary behavior in the model M7 (ps. > .382).

\section{References}

1. Bai, Y., Chen, S., Vazou, S., Welk, G. J., \& Schaben, J. (2015). Mediated Effects of Perceived Competence on Youth Physical Activity and Sedentary Behavior. Research Quarterly for Exercise and Sport, 86(4), 406-413. https://doi.org/10.1080/02701367.2015.1087639

2. Barton, K. (2009). MuMIn: multi-model inference. R package version 1. 0. 0. Http://R-Forge. r-Project. Org/Projects/Mumin/.

3. Bates, D., Mächler, M., Bolker, B., \& Walker, S. (2014). Fitting linear mixed-effects models using Ime4. ArXiv Preprint ArXiv:1406.5823.

4. Biddle, S. J. H. (2011). Fit or sit? Is there a psychology of sedentary behaviour. Sport \& Exercise Psychology Review, 7(2), 5-10.

5. Blackburn, N. E., Wilson, J. J., McMullan, I. I., Caserotti, P., Giné-Garriga, M., Wirth, K., Coll-Planas, L., Alias, S. B., Roqué, M., Deidda, M., Kunzmann, A. T., Dallmeier, D., \& Tully, M. A. (2020). The effectiveness and complexity of interventions targeting sedentary behaviour across the lifespan: a systematic review and meta-analysis. International Journal of Behavioral Nutrition and Physical Activity, 17(1), 53. https://doi.org/10.1186/s12966-020-00957-0

6. Boisgontier, M. P., \& Cheval, B. (2016). The anova to mixed model transition. Neuroscience \& Biobehavioral Reviews, 68, 1004-1005.

7. Bollen, K. A., Harden, J. J., Ray, S., \& Zavisca, J. (2014). BIC and Alternative Bayesian Information Criteria in the Selection of Structural Equation Models. Structural Equation Modeling: A Multidisciplinary Journal, 21(1), 1-19. https://doi.org/10.1080/10705511.2014.856691 
8. Brand, R., \& Cheval, B. (2019). Theories to Explain Exercise Motivation and Physical Inactivity: Ways of Expanding Our Current Theoretical Perspective. Frontiers in Psychology, 10, 1147. https://doi.org/10.3389/fpsyg.2019.01147

9. Buck, C., Loyen, A., Foraita, R., Van Cauwenberg, J., De Craemer, M., Mac Donncha, C., Oppert, J.-M., Brug, J., Lien, N., Cardon, G., Pigeot, I., Chastin, S., \& Consortium, on behalf of the D. (2019). Factors influencing sedentary behaviour: A system based analysis using Bayesian networks within DEDIPAC. Plos One, 14(1), e0211546. https://doi.org/10.1371/journal.pone.0211546

10. Busschaert, C., De Bourdeaudhuij, I., Van Cauwenberg, J., Cardon, G., \& De Cocker, K. (2016). Intrapersonal, social-cognitive and physical environmental variables related to context-specific sitting time in adults: a one-year follow-up study. International Journal of Behavioral Nutrition and Physical Activity, 13(1), 28.

11. Chan, C., \& Ryan, D. (2009). Assessing the Effects of Weather Conditions on Physical Activity Participation Using Objective Measures. International Journal of Environmental Research and Public Health, 6(10), 2639-2654. https://doi.org/10.3390/ijerph6102639

12. Chastin, S. F. M., Buck, C., Freiberger, E., Murphy, M., Brug, J., Cardon, G., O’Donoghue, G., Pigeot, I., \& Oppert, J.-M. (2015). Systematic literature review of determinants of sedentary behaviour in older adults: a DEDIPAC study. International Journal of Behavioral Nutrition and Physical Activity, 12(1), 127.

13. Cheval, B., Daou, M., Cabral, D. A. R., Bacelar, M. F. B., Parma, J. O., Forestier, C., Orsholits, D., Sander, D., Boisgontier, M. P., \& Miller, M. W. (2020). Higher inhibitory control is required to escape the innate attraction to effort minimization. Psychology of Sport and Exercise, 51, 101781.

14. https://doi.org/10.1016/j.psychsport.2020.101781

15. Cheval, B., Radel, R., Neva, J. L., Boyd, L. A., Swinnen, S. P., Sander, D., \& Boisgontier, M. P. (2018). Behavioral and neural evidence of the rewarding value of exercise behaviors: A systematic review. Sports Medicine, 48(6), 1389-1404. https://doi.org/10.1007/s40279-018-0898-0

16. Cheval, B., Sarrazin, P., Boisgontier, M. P., \& Radel, R. (2017). Temptations toward behaviors minimizing energetic costs (BMEC) automatically activate physical activity goals in successful exercisers. Psychology of Sport and Exercise, 30,110-117. https://doi.org/10.1016/j.psychsport.2017.02.006

17. Cheval, B., Sarrazin, P., Isoard-Gautheur, S., Radel, R., \& Friese, M. (2015). Reflective and impulsive processes explain (in)effectiveness of messages promoting physical activity: A randomized controlled trial. Health Psychology, 34(1), 10-19. https://doi.org/10.1037/hea0000102

18. Cheval, B., Sarrazin, P., Isoard-Gautheur, S., Radel, R., \& Friese, M. (2016). How impulsivity shapes the interplay of impulsive and reflective processes involved in objective physical activity. Personality and Individual Differences, 96, 132-137. https://doi.org/10.1016/j.paid.2016.02.067

19. Cheval, B., Sarrazin, P., \& Pelletier, L. (2014). Impulsive approach tendencies towards physical activity and sedentary behaviors, but not reflective intentions, prospectively predict non-exercise activity thermogenesis. Plos One, 9(12), e115238. 
20. Cheval, B., Tipura, E., Burra, N., Frossard, J., Chanal, J., Orsholits, D., Radel, R., \& Boisgontier, M. P. (2018). Avoiding sedentary behaviors requires more cortical resources than avoiding physical activity: An EEG study. Neuropsychologia, 119, 68-80.

https://doi.org/10.1016/j.neuropsychologia.2018.07.029

21. Chevance, G., Héraud, N., Varray, A., \& Boiché, J. (2017). Change in explicit and implicit motivation toward physical activity and sedentary behavior in pulmonary rehabilitation and associations with postrehabilitation behaviors. Rehabilitation Psychology, 62(2), 119-129.

https://doi.org/10.1037/rep0000137

22. Conroy, D. E., \& Berry, T. R. (2017). Automatic affective evaluations of physical activity. Exercise and Sport Sciences Reviews, 45(4), 230-237.

23. Conroy, D. E., Maher, J. P., Elavsky, S., Hyde, A. L., \& Doerksen, S. E. (2013). Sedentary behavior as a daily process regulated by habits and intentions. Health Psychology, 32(11), 1149.

24. Cousineau, D., \& Chartier, S. (2010). Outliers detection and treatment: a review. International Journal of Psychological Research, 3(1), 58-67. https://doi.org/10.21500/20112084.844

25. De Craemer, M., Chastin, S., Ahrens, W., Bernaards, C., Brug, J., Buck, C., Cardon, G., Capranica, L., Dargent-Molina, P., \& De Lepeleere, S. (2018). Data on determinants are needed to curb the sedentary epidemic in Europe. Lessons learnt from the DEDIPAC European knowledge hub. International Journal of Environmental Research and Public Health, 15(7), 1406.

26. Diaz, K. M., Howard, V. J., Hutto, B., Colabianchi, N., Vena, J. E., Blair, S. N., \& Hooker, S. P. (2016). Patterns of Sedentary Behavior in US Middle-Age and Older Adults: The REGARDS Study. Medicine and Science in Sports and Exercise, 48(3), 430-438.

https://doi.org/10.1249/MSS.0000000000000792

27. Evenson, K. R., \& Terry, J. W. (2009). Assessment of Differing Definitions of Accelerometer Nonwear Time. Research Quarterly for Exercise and Sport, 80(2), 355-362.

https://doi.org/10.1080/02701367.2009.10599570

28. Freedson, P. S., Melanson, E., \& Sirard, J. (1998). Calibration of the Computer Science and Applications, Inc. accelerometer: Medicine \& Science in Sports \& Exercise, 30(5), 777-781.

29. https://doi.org/10.1097/00005768-199805000-00021

30. Frossard, J., \& Renaud, O. (2019). The correlation structure of mixed effects models with crossed random effects in controlled experiments. http://arxiv.org/abs/1903.10766

31. Gardner, B. (2015). A review and analysis of the use of 'habit' in understanding, predicting and influencing health-related behaviour. Health Psychology Review, 9(3), 277-295. https://doi.org/10.1080/17437199.2013.876238

32. Gardner, B., Flint, S., Rebar, A. L., Dewitt, S., Quail, S. K., Whall, H., \& Smith, L. (2019). Is sitting invisible? Exploring how people mentally represent sitting. International Journal of Behavioral Nutrition and Physical Activity, 16(1), 85.

33. https://doi.org/10.1186/s12966-019-0851-0 
34. Gardner, B., Smith, L., Lorencatto, F., Hamer, M., \& Biddle, S. J. H. (2016). How to reduce sitting time? A review of behaviour change strategies used in sedentary behaviour reduction interventions among adults. Health Psychology Review, 10(1), 89-112. https://doi.org/10.1080/17437199.2015.1082146

35. Glass, T. A., \& McAtee, M. J. (2006). Behavioral science at the crossroads in public health: extending horizons, envisioning the future. Social Science \& Medicine, 62(7), 1650-1671.

36. Gollwitzer, P. M., \& Sheeran, P. (2006). Implementation Intentions and Goal Achievement: A Metaanalysis of Effects and Processes. In Advances in Experimental Social Psychology (Vol. 38, pp. 69119). Elsevier. https://linkinghub.elsevier.com/retrieve/pii/S0065260106380021

37. Gupta, N., Heiden, M., Aadahl, M., Korshøj, M., Jørgensen, M. B., \& Holtermann, A. (2016). What Is the Effect on Obesity Indicators from Replacing Prolonged Sedentary Time with Brief Sedentary Bouts, Standing and Different Types of Physical Activity during Working Days? A Cross-Sectional Accelerometer-Based Study among Blue-Collar Workers. PLOS ONE, 11(5), e0154935.

38. https://doi.org/10.1371/journal.pone.0154935

39. Hagger, M. S. (2020). Redefining habits and linking habits with other implicit processes. Psychology of Sport and Exercise, 46, 101606.

40. https://doi.org/10.1016/j.psychsport.2019.101606

41. Ham, O. K., Sung, K. M., \& Kim, H. K. (2013). Factors associated with screen time among school-age children in Korea. The Journal of School Nursing, 29(6), 425-434.

42. Hamilton, M. T., Hamilton, D. G., \& Zderic, T. W. (2007). Role of low energy expenditure and sitting in obesity, metabolic syndrome, type 2 diabetes, and cardiovascular disease. Diabetes, 56(11), 26552667.

43. He, M., Piché, L., Beynon, C., \& Harris, S. (2010). Screen-related Sedentary Behaviors: Children's and Parents' Attitudes, Motivations, and Practices. Journal of Nutrition Education and Behavior, 42(1), 17-25. https://doi.org/10.1016/j.jneb.2008.11.011

44. Healy, G. N., Clark, B. K., Winkler, E. A. H., Gardiner, P. A., Brown, W. J., \& Matthews, C. E. (2011). Measurement of Adults' Sedentary Time in Population-Based Studies. American Journal of Preventive Medicine, 41(2), 216-227. https://doi.org/10.1016/j.amepre.2011.05.005

45. Jankowska, M. M., Schipperijn, J., \& Kerr, J. (2015). A framework for using GPS data in physical activity and sedentary behavior studies. Exercise and Sport Sciences Reviews, 43(1), 48.

46. Judd, C. M., Westfall, J., \& Kenny, D. A. (2017). Experiments with more than one random factor: Designs, analytic models, and statistical power. Annual Review of Psychology, 68, 601-625.

47. Karpinski, A., \& Steinman, R. B. (2006). The single category implicit association test as a measure of implicit social cognition. Journal of Personality and Social Psychology, 91(1), 16.

48. Krieglmeyer, R., \& Deutsch, R. (2010). Comparing measures of approach-avoidance behaviour: The manikin task vs. two versions of the joystick task. Cognition \& Emotion, 24(5), 810-828. https://doi.org/10.1080/02699930903047298 
49. Kuznetsova, A., Brockhoff, P. B., \& Christensen, R. H. B. (2015). Package 'Imertest.' R Package Version, 2(0).

50. Levine, J. A. (2015). Sick of sitting. Diabetologia, 58(8), 1751-1758.

51. Lund Rasmussen, C., Palarea-Albaladejo, J., Korshøj, M., Gupta, N., Nabe-Nielsen, K., Holtermann, A., \& Jørgensen, M. B. (2019). Is high aerobic workload at work associated with leisure time physical activity and sedentary behaviour among blue-collar workers? A compositional data analysis based on accelerometer data. PLOS ONE, 14(6), e0217024. https://doi.org/10.1371/journal.pone.0217024

52. Maher, J. P., \& Conroy, D. E. (2015). Habit strength moderates the effects of daily action planning prompts on physical activity but not sedentary behavior. Journal of Sport and Exercise Psychology, 37(1), 97-107.

53. Maher, J. P., \& Conroy, D. E. (2016). A dual-process model of older adults' sedentary behavior. Health Psychology, 35(3), 262-272. https://doi.org/10.1037/hea0000300

54. Maher, J. P., \& Dunton, G. F. (2019). Dual-process model of older adults' sedentary behavior: an ecological momentary assessment study. Psychology \& Health, 1-19.

55. Maher, J. P., \& Dunton, G. F. (2020). Within-day time-varying associations between motivation and movement-related behaviors in older adults. Psychology of Sport and Exercise, 47, 101522. https://doi.org/10.1016/j.psychsport.2019.04.012

56. Matthews, C. E., Hagströmer, M., Pober, D. M., \& Bowles, H. R. (2012). Best Practices for Using Physical Activity Monitors in Population-Based Research: Medicine \& Science in Sports \& Exercise, 44, S68-S76.

57. https://doi.org/10.1249/MSS.0b013e3182399e5b

58. Melanson, E. L. (2017). The effect of exercise on non-exercise physical activity and sedentary behavior in adults. In Obesity Reviews (Vol. 18, Issue Suppl 1, pp. 40-49). Blackwell Publishing Ltd.

59. https://doi.org/10.1111/obr.12507

60. Migueles, J. H., Cadenas-Sanchez, C., Ekelund, U., Delisle Nyström, C., Mora-Gonzalez, J., Löf, M., Labayen, I., Ruiz, J. R., \& Ortega, F. B. (2017). Accelerometer Data Collection and Processing Criteria to Assess Physical Activity and Other Outcomes: A Systematic Review and Practical Considerations. Sports Medicine, 47(9), 1821-1845. https://doi.org/10.1007/s40279-017-0716-0

61. Motl, R. W., McAuley, E., \& Dlugonski, D. (2012). Reactivity in baseline accelerometer data from a physical activity behavioral intervention. Health Psychology, 31(2), 172-175.

https://doi.org/10.1037/a0025965

62. O'Donoghue, G., Perchoux, C., Mensah, K., Lakerveld, J., Van Der Ploeg, H., Bernaards, C., Chastin, S. F. M., Simon, C., O'gorman, D., \& Nazare, J.-A. (2016). A systematic review of correlates of sedentary behaviour in adults aged 18-65 years: a socio-ecological approach. BMC Public Health, 16(1), 163.

63. Olanrewaju, O., Stockwell, S., Stubbs, B., \& Smith, L. (2020). Sedentary behaviours, cognitive function, and possible mechanisms in older adults: A systematic review. Aging Clinical and Experimental Research, 1-16. 
64. Owen, N., Sugiyama, T., Eakin, E. E., Gardiner, P. A., Tremblay, M. S., \& Sallis, J. F. (2011). Adults' Sedentary Behavior. American Journal of Preventive Medicine, 41(2), 189-196.

65. https://doi.org/10.1016/j.amepre.2011.05.013

66. Patel, A. V, Bernstein, L., Deka, A., Feigelson, H. S., Campbell, P. T., Gapstur, S. M., Colditz, G. A., \& Thun, M. J. (2010). Leisure time spent sitting in relation to total mortality in a prospective cohort of US adults. American Journal of Epidemiology, 172(4), 419-429.

67. Prapavessis, H., Gaston, A., \& DeJesus, S. (2015). The theory of planned behavior as a model for understanding sedentary behavior. Psychology of Sport and Exercise, 19, 23-32.

68. Prince, S. A., Saunders, T. J., Gresty, K., \& Reid, R. D. (2014). A comparison of the effectiveness of physical activity and sedentary behaviour interventions in reducing sedentary time in adults: a systematic review and meta-analysis of controlled trials: Interventions and sedentary behaviours. Obesity Reviews, 15(11), 905-919. https://doi.org/10.1111/obr.12215

69. Quartiroli, A., \& Maeda, H. (2014). Self-determined engagement in physical activity and sedentary behaviors of US college students. International Journal of Exercise Science, 7(1), 87.

70. Rawlings, G. H., Williams, R. K., Clarke, D. J., English, C., Fitzsimons, C., Holloway, I., Lawton, R., Mead, G., Patel, A., \& Forster, A. (2019). Exploring adults' experiences of sedentary behaviour and participation in non-workplace interventions designed to reduce sedentary behaviour: a thematic synthesis of qualitative studies. BMC Public Health, 19(1), 1099.

71. Rebar, A L, Rosenbaum, S., \& Maher, J. P. (2020). Responsiveness to change of the psychological determinants and outcomes of physical activity and sedentary behavior. Psychology of Sport and Exercise, 49, 101706. https://doi.org/10.1016/j.psychsport.2020.101706

72. Rebar, Amanda L, Gardner, B., Rhodes, R. E., \& Verplanken, B. (2018). The measurement of habit. In The psychology of habit (pp. 31-49). Springer.

73. Rebar, Amanda L, Ram, N., \& Conroy, D. E. (2015). Using the EZ-diffusion model to score a SingleCategory Implicit Association Test of physical activity. Psychology of Sport and Exercise, 16, 96105. https://doi.org/10.1016/j.psychsport.2014.09.008

74. Rhodes, R. E., \& Blanchard, C. M. (2011). Time displacement and confidence to participate in physical activity. International Journal of Behavioral Medicine, 18(3), 229-234.

75. Rhodes, R. E., Brown, S. G., \& Mclntyre, C. A. (2006). Integrating the Perceived Neighborhood Environment and the Theory of Planned Behavior When Predicting Walking in a Canadian Adult Sample. American Journal of Health Promotion, 21(2), 110-118. https://doi.org/10.4278/08901171-21.2.110

76. Rhodes, R. E., \& Dean, R. N. (2009). Understanding Physical Inactivity: Prediction of Four Sedentary Leisure Behaviors. Leisure Sciences, 31(2), 124-135. https://doi.org/10.1080/01490400802685948

77. Rhodes, R. E., Mark, R. S., \& Temmel, C. P. (2012). Adult sedentary behavior: a systematic review. American Journal of Preventive Medicine, 42(3), 3-28.

78. Rhodes, R. E., McEwan, D., \& Rebar, A. L. (2019). Theories of physical activity behaviour change: A history and synthesis of approaches. Psychology of Sport and Exercise, 42, 100-109. 
79. https://doi.org/10.1016/j.psychsport.2018.11.010

80. Rollo, S., Gaston, A., \& Prapavessis, H. (2016). Cognitive and motivational factors associated with sedentary behavior: a systematic review. AIMS Public Health, 3(4), 956.

81. Rollo, S., \& Prapavessis, H. (2020). A Combined Health Action Process Approach and mHealth Intervention to Increase Non-Sedentary Behaviours in Office-Working Adults-A Randomised Controlled Trial. Applied Psychology: Health and Well-Being, aphw.12201.

82. https://doi.org/10.1111/aphw.12201

83. Saidj, M., Menai, M., Charreire, H., Weber, C., Enaux, C., Aadahl, M., Kesse-Guyot, E., Hercberg, S., Simon, C., \& Oppert, J.-M. (2015). Descriptive study of sedentary behaviours in 35,444 French working adults: cross-sectional findings from the ACTI-Cités study. BMC Public Health, 15(1), 379.

84. https://doi.org/10.1186/s12889-015-1711-8

85. Schwarzer, R. (2008). Modeling Health Behavior Change: How to Predict and Modify the Adoption and Maintenance of Health Behaviors. Applied Psychology, 57(1), 1-29.

https://doi.org/10.1111/j.1464-0597.2007.00325.x

86. Sedentary Behavior Research Network (2012). Letter to the editor: standardized use of the terms" sedentary" and" sedentary behaviours". Applied Physiology, Nutrition, and Metabolism, 37(3), 540.

87. Sniehotta, F. F., Araújo-Soares, V., Brown, J., Kelly, M. P., Michie, S., \& West, R. (2017). Complex systems and individual-level approaches to population health: a false dichotomy? The Lancet Public Health, 2(9), 396-397.

88. https://doi.org/10.1016/S2468-2667(17)30167-6

89. Spence, J. C., Rhodes, R. E., \& Carson, V. (2017). Challenging the dual-hinge approach to intervening on sedentary behavior. American Journal of Preventive Medicine, 52(3), 403-406.

90. Stamatakis, E., Coombs, N., Rowlands, A., Shelton, N., \& Hillsdon, M. (2014). Objectively-assessed and self-reported sedentary time in relation to multiple socioeconomic status indicators among adults in England: a cross-sectional study. BMJ Open, 4(11), e006034.

https://doi.org/10.1136/bmjopen-2014-006034

91. Strack, F., \& Deutsch, R. (2004). Reflective and impulsive determinants of social behavior. Personality and Social Psychology Review, 8(3), 220-247.

92. Sui, W., \& Prapavessis, H. (2018). Standing Up for Student Health: An Application of the Health Action Process Approach for Reducing Student Sedentary Behavior-Randomised Control Pilot Trial. Applied Psychology: Health and Well-Being, 10(1), 87-107. https://doi.org/10.1111/aphw.12105

93. Teychenne, M., Ball, K., \& Salmon, J. (2010). Sedentary Behavior and Depression Among Adults: A Review. International Journal of Behavioral Medicine, 17(4), 246-254. https://doi.org/10.1007/s12529-010-9075-z

94. Thorp, A. A., Healy, G. N., Winkler, E., Clark, B. K., Gardiner, P. A., Owen, N., \& Dunstan, D. W. (2012). Prolonged sedentary time and physical activity in workplace and non-work contexts: a cross- 
sectional study of office, customer service and call centre employees. International Journal of Behavioral Nutrition and Physical Activity, 9(1), 128.

95. https://doi.org/10.1186/1479-5868-9-128

96. Tigbe, W. W., Lean, M. E. J., \& Granat, M. H. (2011). A physically active occupation does not result in compensatory inactivity during out-of-work hours. Preventive Medicine, 53(1-2), 48-52.

97. https://doi.org/10.1016/j.ypmed.2011.04.018

98. van Uffelen, J. G. Z., Heesch, K. C., \& Brown, W. (2012). Correlates of Sitting Time in Working Age Australian Women: Who Should Be Targeted With Interventions to Decrease Sitting Time? Journal of Physical Activity and Health, 9(2), 270-287. https://doi.org/10.1123/jpah.9.2.270

99. Vandelanotte, C., Duncan, M. J., Short, C., Rockloff, M., Ronan, K., Happell, B., \& Di Milia, L. (2013). Associations between occupational indicators and total, work-based and leisure-time sitting: a crosssectional study. BMC Public Health, 13(1), 1110. https://doi.org/10.1186/1471-2458-13-1110

100. Vandelanotte, C., Sugiyama, T., Gardiner, P., \& Owen, N. (2009). Associations of leisure-time internet and computer use with overweight and obesity, physical activity and sedentary behaviors: Crosssectional study. Journal of Medical Internet Research, 11(3). https://doi.org/10.2196/jmir.1084

101. Zenko, Z., \& Ekkekakis, P. (2019). Internal consistency and validity of measures of automatic exercise associations. Psychology of Sport and Exercise, 43, 4-15.

https://doi.org/10.1016/j.psychsport.2018.12.005

\section{Figures}

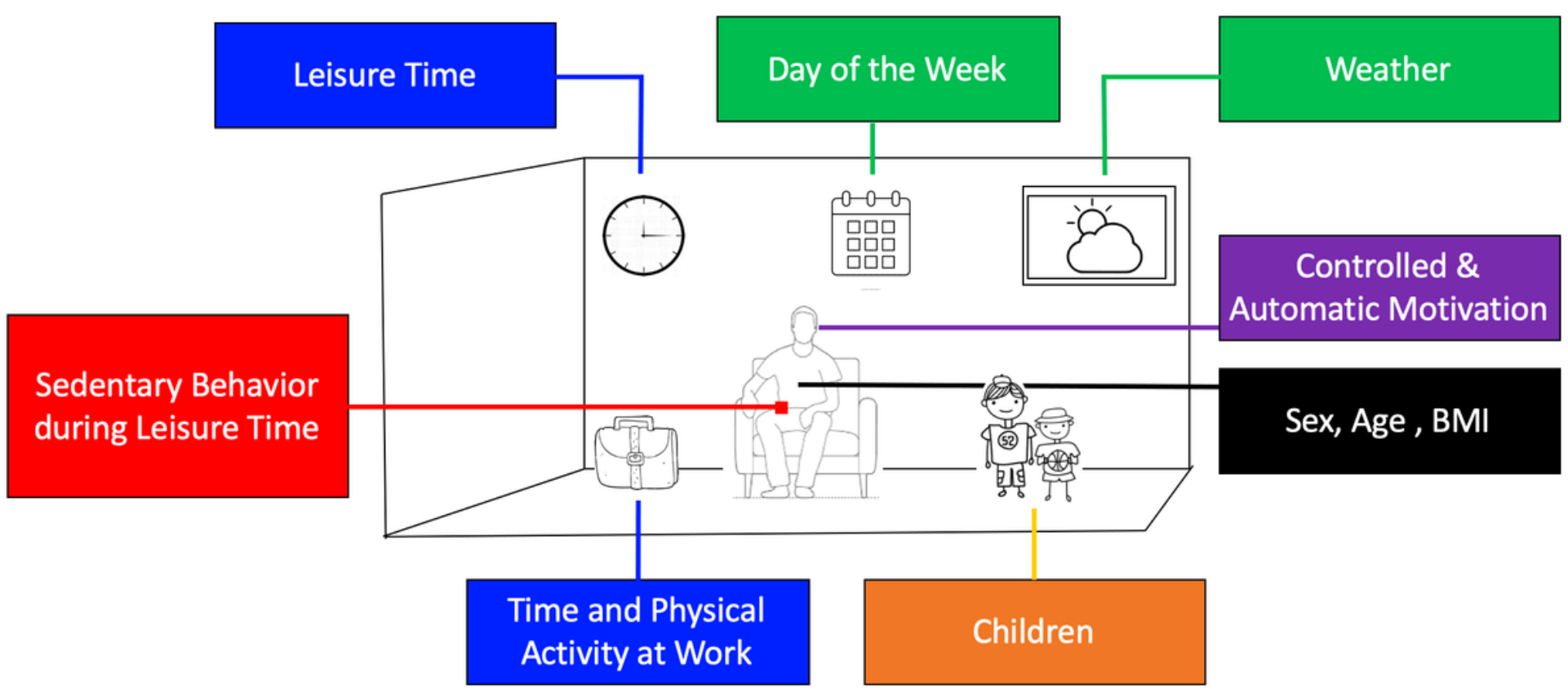

Figure 1 
Predictive variables and outcome included in the mixed models Note. Outcome (red), motivational (purple), demographic (black), physical (black), socio-professional (blue), interpersonal (orange), and environmental (green) used in this study. Controlled motivational variables included attitudes, intentions and competence. Automatic motivational variables included habit strength and approach-avoidance tendencies. BMI: body mass index.

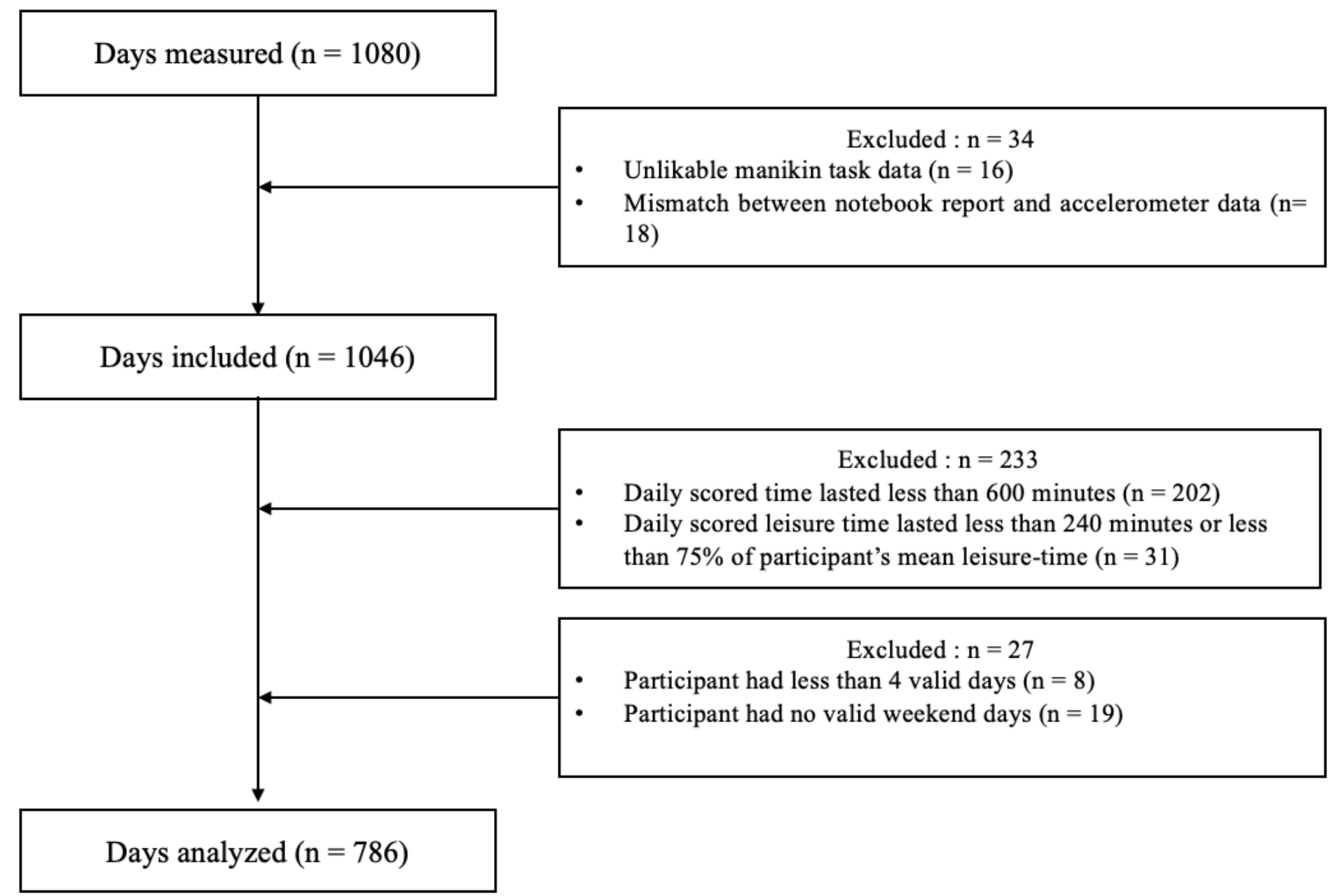

Figure 2

Flow diagram 
Predicting leisure-time sedentary behaviors

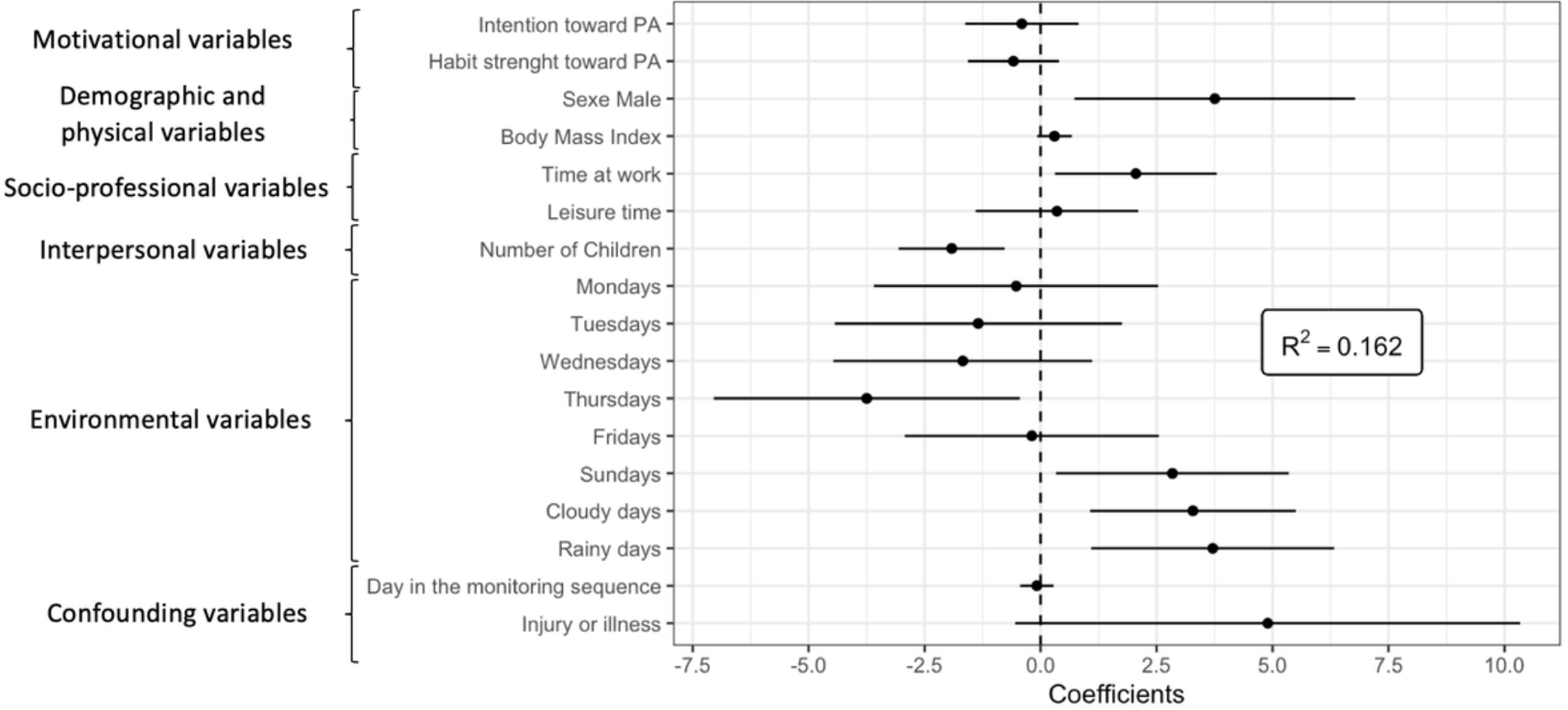

Figure 3

Associations of variables entered in the final model M6 with leisure-time sedentary behaviors Note.

Coefficients b, 95\% confidence interval are reported. Female individuals, Saturdays and absence of injury or illness served as references for sex, days of the week and illness/injury, respectively.

\section{Supplementary Files}

This is a list of supplementary files associated with this preprint. Click to download.

- SBSupplementarymaterial.docx

- OnlineFig1SB.Png

- OnlineFig2SB.Png

- OnlineFig3SB.Png 